\title{
Comparison of deferasirox and deferoxamine effect on liver enzyme activities and ferritin level in patients with beta-thalassemia
}

\section{Abstract}

Background and objective: Patients on blood transfusion may develop complications related to iron overload and the effects of chelating agents (drugs), which adversely affect the liver in thalassemia, which is a genetic blood disorder of hemoglobin synthesis that causes severe anemia. This study aimed to assess the effect of deferasirox and deferoxamine drugs on liver enzyme activities (aspartate transaminase, alanine transaminase, and alkaline phosphatase), and serum ferritin level in $\beta$ _thalassemic patients.

Methods: This study was carried out in Erbil city from October 2017 to February 2018. Blood specimens were collected in Hawler thalassemia center and Raparin hospital. The samples included 105 individuals; $70 \beta$-thalassemic patients (35 treated by deferasirox as group $\mathrm{A}$ and 35 treated by deferoxamine as group B), and 35 healthy individuals (control group C).

Results: The serum aspartate transaminase and alkaline phosphatase activities in $\beta$-thalassemic patients were higher than that of controls. The serum alanine transaminase activity in the patients' groups showed non-significant elevation than that of controls. The serum ferritin level in the patients was significantly higher than that of controls.

Conclusion: Our finding showed that both deferasirox and deferoxamine drugs affect liver enzymes and increase ferritin level.

Keywords: $\beta$-thalassemia; Deferasirox; Deferoxamine; Liver enzymes; Ferritin.

\section{Introduction}

Thalassemia is a heterogeneous group of genetic disorders of hemoglobin synthesis characterized by a reduction in the synthesis of one or more of the globin chains leads to imbalanced globin -chain synthesis, defective hemoglobin production causing anemia. ${ }^{1,2}$ Thalassemia is a genetic blood disorder. People with thalassemia disease are not able to make enough hemoglobin, which causes severe anemia. Hemoglobin is found in red blood cells and carries oxygen to all parts of the body. When there is not enough hemoglobin in the red blood cells, oxygen cannot get to all parts of the body. Organs then become starved for oxygen and are unable to function properly. There are two primary types of thalassemia disease, alpha thalassemia disease and beta-thalassemia disease. ${ }^{2-4} \beta$-thalassemia major (also called Cooley's Anemia) is the most severe form of $\beta$-thalassemia. The complete lack of beta-globin production prevents the production of significant amounts of hemoglobin. The severe imbalance of globin chain synthesis (alpha > beta) results in ineffective erythropoiesis and severe microcytic hypochromic anemia. The excess unpaired alpha-globin chains aggregate to form precipitates that damage red cell membranes, resulting in intravascular hemolysis. Premature destruction of erythroid precursors results in intramedullary death and ineffective

${ }_{1}^{1}$ Department of Clinical Biochemistry, College of Health Sciences, Hawler Medical University, Erbil, I raq.

2 Department of Clinical Biochemistry, College of Medicine, Hawler Medical University, Erbil, I raq.

* Correspondence: dlerra2003@yahoo.com 
erythropoiesis. The profound anemia typically is associated with erythroid hyperplasia and extramedullary hematopoiesis. ${ }^{4,5}$ In $\beta$-thalassemia patients, chronic iron overload represents a serious complication of potentiallylifesaving blood transfusions. Excess iron deposits in various body tissues, particularly the liver, heart, and endocrine organs. Both deferasirox and deferoxamine are iron -chelating substances to reduce iron over loud in thalassemiapatients. ${ }^{6}$ This study aimed to determine the effect of these drugs on liver enzyme activities ((aspartate transaminase (AST), alanine transaminase (ALT), and alkaline phosphatase (ALP)), and serum ferritin level in $\beta$-thalassemia patients.

\section{Methods}

Subject: The protocol of the study was carried out from October 2017 to February 2018. The patient's age was in the range of 3-12 years. A cross-sectional analysis study designed to investigate the compilation between the variation in serum level of liver enzymes in 70 patients with known cases of beta-thalassemia major from both gender (males and females) who have been treated with blood transfusion and iron chelators. All patients were diagnosed as having $\beta$-thalassemia major by hematologist physicians depending on hemoglobin variants test by hemoglobin electrophoresis. Patients were divided according to the type of therapy into two groups. Group A included 35 transfusion-dependent $\beta$-thalassemia patients receiving deferasirox (an oral iron-chelating), with a daily dose of 10-30 $\mathrm{mg} / \mathrm{kg}$ according to the age and body weight. Group B included 35 transfusiondependent $\beta$-thalassemia patients receiving deferoxamine (as an IV or SC iron chelating) infusion (8 h/day) $30 \mathrm{mg} / \mathrm{kg} / \mathrm{each}$ 3 days/week. Group C (Control group) included 35 apparently healthy children who had no chronic disease and had not received any therapy were included in the study.

\section{Methods}

Determination of Serum alkaline phosphate (ALP)

The serum ALP was estimated using the Cobas diagnostic kit (Roche/Hitachi Cobas c 311). In vitro test was used for the quantitative determination of alkaline phosphatase in human serum and plasma on Roche/Hitachi Cobas c systems, with a fully automated chemical analyzer. ${ }^{7,8}$

Determination of Serum alanine aminotransferase (ALT):

The ALT was estimated by using Cobas diagnostic kit (Roche/Hitachi Cobas c311), with a fully automated chemical analyzer. ${ }^{7,8}$

Determination of Serum aspartate aminotransferase (AST):

The AST was estimated by using Cobas diagnostic kit (Roche/COBAS 311 INTEGRA), with a fully automated chemical analyzer. The method for detecting AST (Aspartate Aminotransferase - Pyridoxal phosphate activated) was used for this research. ${ }^{7,8}$

\section{Determination of Serum Ferritin: Principle}

The assay principle combines a one-step enzyme immunoassay sandwich method a final fluorescent detection. The solid phase receptacle (SPR) serves as the solid phase as well as the pipetting device for the assay. Reagents for the assay are ready-to-use and predisposed in the sealed reagent strips. All of the assay steps are performed automatically by the instrument. The reaction medium is cycled in and out of the SPR several times. During the final detection step, the substrate (4-Methyl-umbelliferyl phosphate) is cycled in and out of the SPR. The conjugate enzyme catalyzes the hydrolysis of the substrate into a fluorescence of which is measured at $450 \mathrm{~nm}$. The intensity of the fluorescence is proportional to the concentration of the antigens present in the sample. ${ }^{9}$ At the end of the assay, results are automatically calculated by the instrument. 


\section{Statistical analysis:}

The statistical analysis of this study was performed using the statistical package for the social sciences (version 22.0). Chi-square test was used to assess the statistical significance of association among proportions. A $P$ value of $\leq 0.05$ was considered statistically significant.

\section{Results}

The liver enzyme activities of $\beta$-thalassemic groups (A and $B$ ) are shown in Table 1. The mean \pm SE values of serum ALP, ALT, and AST activities and serum ferritin in two subgroups ( $A$ and $B$ ) of $\beta$-thalassemic patients were elevated significantly compared with those of controls. It also seems that the used drugs caused a significant secretion in the total ferritin protein. The liver enzymatic parameters of $\beta$-thalassemic group $A$ and control group (C) are shown in Table 2. In the current study, the mean \pm SE values of serum ALP and AST levels were significantly higher $(P<0.001)$ in $\beta$-thalassemic (group A) when compared with the control group. The mean $\pm S E$ value of serum ALT was nonsignificantly higher in $\beta$-thalassemic (group A) when compared with the control group. The serum level of ferritin in $\beta$-thalassemic (group A) was significantly higher than that of the control group (C).

Table 1: Mean \pm SE of the enzyme activities (AST, ALT, ALP) and ferritin level (ng/ml) in two $\beta$-thalassemic group $A$ and group $B$.

\begin{tabular}{lcc}
\hline \multirow{2}{*}{ Parameter } & \multicolumn{2}{c}{ Mean \pm SE } \\
\hline AST U/L & Group A n=35 & Group B n=35 \\
ALT U/L & $47.025 \pm 9.02$ & $75.95 \pm 14.49$ \\
ALP U/L & $42.29 \pm 11.31$ & $60.53 \pm 14.36$ \\
Ferritin (ng/ml) & $432.58 \pm 41.14$ & $401.47 \pm 25.54$ \\
\hline
\end{tabular}

Table 2: Mean \pm SE of the enzyme activities (AST, ALT, ALP) and ferritin level (ng/ml) in $\beta$-thalassemic group $A$ and control group $C$.

\begin{tabular}{|c|c|c|c|c|}
\hline \multirow{2}{*}{\multicolumn{2}{|c|}{ Parameter }} & \multicolumn{2}{|c|}{ Mean \pm SE } & \multirow{2}{*}{$P$ value } \\
\hline & & Group A n=35 & Group $C n=35$ & \\
\hline AST & U/L & $47.025 \pm 9.02$ & $24.45 \pm 1.099$ & 0.020 \\
\hline ALT & U/L & $42.29 \pm 11.31$ & $26.26 \pm 1.016$ & 0.162 \\
\hline ALP & U/L & $432.58 \pm 41.14$ & $183.57 \pm 7.456$ & 0.001 \\
\hline \multicolumn{2}{|c|}{ Ferritin (ng/ml) } & $2619.51 \pm 331.4$ & $169.100 \pm 11.377$ & 0.001 \\
\hline
\end{tabular}


The results of the Liver enzyme activities of $\beta$-thalassemic group $B$ and control group (C) are shown in Table 3. In the current study, the mean $\pm S E$ values of serum ALP and AST levels were significantly higher $(P<0.001)$ in $\beta$-thalassemic (group B) when compared with the control group. The mean $\pm S E$ value of serum ALT was nonsignificantly higher in $\beta$-thalassemic (group B) when compared with the control group. The serum level of ferritin in $\beta$-thalassemic (group B) was significantly higher than that of the control group (group C).

\section{Discussion}

Liver enzymes can be divided into different groups. Aspartate aminotransferase (AST or GOT) and alanine aminotransferase (ALT or GPT), together these enzymes are known as transaminases. Alkaline phosphatase (ALP) is known as cholestatic liver enzymes. If these enzymes are elevated, it can indicate liver disease and secreted enzymes that are made in the liver and allocated to the blood. 8 The main leading cause of elevated liver enzymes is iron overload. ${ }^{10}$ In the current study, the values of serum ALP and AST levels were significantly higher $(P<0.001)$ in $\beta$-thalassemic groups when compared with the control group. Furthermore, the results showed that the rise in serum ALT activity was nonsignificantlyhigher in $\beta$-thalassemic groups than the control group. This can be explained due to the following disorders correlated with thalassemia. Thus, the data obtained confirm the previously published works. Thalassemic patients suffer from a liver disease such as chronic hepatitis, liver cirrhosis, and hepatocellular carcinoma due to iron overload. ${ }^{11}$ In those cases, elevated SAST and SLP-activity due to secretion of the enzyme into the circulation because of liver damage and alterations in the extent to be which a type of cell capable of producing the enzyme, or increase in the number of cells which are due to an abnormal condition of the liver. ${ }^{12-14}$ Elevated serum ALP-activity may be due to a splenomegaly disorder that thalassemic patients already diagnosed by physicians. This study agrees with that of Bayraker et al., which observed an increase in serum ALP-activity in patients with splenomegaly only. ${ }^{15}$ Liver enzyme functions can be influenced by many personal and environmental factors, including age, gender, body mass index (BMI), malnutrition, and presence of extrahepatic diseases such as cardiac, musculoskeletal, or endocrine diseases. It concluded from the above finding that the $\beta$-thalassemia has a relative risk of liver diseases. Ferritin has been traditionally considered a cytoplasm iron storage protein. However, several studies over the last two decades have reported the nuclear localization of ferritin, specifically $\mathrm{H}$-ferritin, in developing

Table 3: Mean \pm SE of the enzyme activities (AST, ALT, ALP) and ferritin level ( $\mathrm{ng} / \mathrm{ml}$ ) in $\beta$-thalassemic group $B$ and control group $C$.

\begin{tabular}{lccc}
\hline \multirow{2}{*}{ Parameter } & \multicolumn{2}{c}{ Mean \pm SE } & \multirow{2}{*}{ Group B $\mathrm{n}=35$} \\
\hline AST U/L & $75.95 \pm 14.49$ & Group C $\mathbf{n}=35$ & \\
ALT U/L & $60.53 \pm 14.36$ & $24.45 \pm 1.099$ & 0.001 \\
ALP U/L & $401.47 \pm 25.54$ & $183.57 \pm 7.456$ & 0.023 \\
Ferritin $(\mathrm{ng} / \mathrm{ml})$ & $2750.84 \pm 29.27$ & $169.100 \pm 11.377$ & 0.001 \\
\hline
\end{tabular}


neurons, hepatocytes, corneal epithelial cells, and some cancer cells. This ferritin beyond iron storage, such as a role component, DNA protection form iron-induced oxidative damage, and transcription at regulation. ${ }^{16,17}$ The role of iron in breast cancer could potentially benefit patients by decreasing recurrence and incidence and increasing overall survival. ${ }^{18}$ The present study provides the mean \pm SE serum ferritin in both groups. The results obtained reveal that the mean \pm SE serum ferritin in the $\beta$-thalassemic group was significantly higher than those obtained in the normal group. Serum ferritin is an acute-phase reactant and may be elevated in many conditions, including infections, inflammation, malignancy, thalassemia, and liver disease. ${ }^{19}$ Serum ferritin and iron both show acute phase responses to inflammation. So iron may fall, and ferritin rise independent of the bone marrow iron store ${ }^{20}$ hyperferritinemia is commonly found in chronic inflammatory status or neoplasia. ${ }^{21}$ Multiple factors influence the iron status and ferritin level, which may complicate the interpretation of data. Anemia is often present in breast cancer patients, and iron deficits may be hidden by high ferritin levels, which is elevated due to cancer. In such cases, reticulocyte hemoglobin content and soluble transferrin receptor may be used as sensitive markers of iron deficiency. ${ }^{22}$

\section{Conclusion}

The serum enzyme (AST and ALP) activities in both groups (A and $B$ ) of thalassemic patients were significantly higher than that of controls (group C). The serum ALT enzyme activity in both groups (A and $B$ ) of thalassemic patients was nonsignificantly higher than that of controls (group $C$ ). The serum ferritin levels in both groups (A and B) of thalassemic patients were significantly higher than that of controls (group C). There were no significant differences in serum ALT, AST, ALP activities, and serum ferritin levels between the two groups of $\beta$-thalassemia
( $A$ and $B$ ).

\section{Competing interests}

The authors declare no competing interests.

\section{References}

1. Kanitta S, Saovaros S, Worrakavee C, Jim V, Phantip V, Suthat F, et al. Imbalanced globin chain synthesis determines erythroid cell pathology in thalassemic mice. Haematologica 2009; 94(9):1211-9.

2. Mathews C, Van Holde K, Kevin G. Biochemistry. $3^{\text {rd }}$ ed. New York: An imprint of addition Wesley Longman Inc; 2000. P. 1930-31.

3. Cunningham M, Macklin E, Neufeld E, Cohen A. Complications of beta-thalassemia major in North America. Blood 2004; 104(1):34-9.

4. Pingsen Z, Heming W, Ruiqiang W. Molecular analysis of hemoglobinopathies in a large ethnic Hakka population in southern China. Medicine (Baltimore) 2018; 97(45):e13034.

5. Vanessa S, Manzon. Intensive course in Biological Anthropology 1st Summer School of the European Anthropological Association 2007; EAA Summer School eBook 1:115-25.

6. Maria D, Alan C, Antonio P, Mohamed B, Silverio $P$, Leyla A, et al. A phase 3 study of deferasirox (ICL670), a once-daily oral iron chelator, in patients with Beta-thalassemia. Blood 2006; 107:3455-62.

7. Tietz NW. Textbook of clinical chemistry. $3^{\text {rd }}$ ed. Philadelphia: WB Saunders; 1999; P. 1699-703.

8. Debasish S, Rukmini M, Ravitosh R. Quantitative analysis of serum level alanine and aspartate aminotransferases, $\mathrm{y}$-glutamyl transferase and alkaline phosphatase as predictor of liver diseases. AIJRFANS 2015; 51-5.

9. Burtis CA, Bruns DE. Tietz fundamentals of clinical chemistry and molecular diagnostics. $4^{\text {th }}$ ed. New York: Elsevier sounders; 2006. P. 1191.

10. Salama KM, Ibrahim OM, Kaddah AM, Boseila S, Ismail LA, Hamid MM. Liver enzymes in children with beta-thalassemia major: Correlation with iron overload and viral hepatitis. OA Maced J Med Sci 2015; 3(2):287-92.

11. Kowdley KV. Iron overload in patients with chronic liver disease. Gastroenterol Hepatol (N Y) 2016;12(11):695-8.

12. Mehta KJ, Farnaud SJ, Sharp PA. Iron and liver fibrosis: Mechanistic and clinical aspects. World J Gastroenterol 2019; 25(5):521-38.

13. Mitchell R. The past and present of serum aminotransferases and the future of liver injury biomarkers. EXCLI J 2016; 15:817-28.

14. Ashraf S, Mohamed $Y$, Fawzia $Y$, Lolwa N, Noora A, Aml S, et al. Longitudinal study on liver functions in patients with thalassemia major before and after deferasirox (DFX) 
therapy. Mediterr J. Hematol Infect Dis 2014; 6(1): e2014025.

15. Bayraker Y, Balkanci F, Ozenc A, Koseoglu T, Ozdemir A. The (pseudo-cholangiocarcinoma sign) in patients with cavernous transformation of the portal vein and its effect on the serum alkaline phosphatase and bilirubin levels. Am J Gastrointestinal 1995; 90:2015-9.

16. Li C, Chik K, Lam C, To K, Yu S, Lee V, et al. Liver disease in transfusion dependent thalassaemia major. Arch Dis Child 2002; 86(5): 344-7.

17. Alkhateeb A, Conner J. Nuclear ferritin: A new role for ferritin in cell. Biology-Biochem. Biophys Acta 2010; 1800(8):793-7.

18. Huang $X$. Does iron has a role in breast cancer? Lancet Oncol 2008; 9(8):803-7.

19. Gangadhar T, Srikanth P, Suneetha Y. Predictive value of iron store markersin anemia of chronic kidney disease. Journal of Chemical and Pharmaceutical Research 2010; 2(3):400-10.

20. Nadeem S, Shah S, Touqueer I, Zafar I, Ejaz H. Serum transferrin receptor, serum ferritin and serum transferring receptor-ferritin index in adults with iron deficiency anaemia. J Ayub Med Coll Abbottabad 2011; 23(3):44-6.

21. Amanda J, Dorine W, Ina S, Jack F. Serum ferritin levels are increased in patients with glomerular diseases and proteinuria. Nephrol Dial Transplant 2004; 19(11):2754-60.

22. Markovic M, Majkic-Singh N, Lgnjatovic S, Singh S. Reticulocyte hemoglobin content versus soluble transferrin receptor and ferritin index in iron deficiency anemia accompanied with inflammation. Int J Lab Hematol 2007; 29:341-6. 